\title{
The Future Medical Science and Colorectal Surgeons
}

\author{
Young Jin Kim \\ Department of Surgery, Chonnam National University Hwasun Hospital, Chonnam National University Medical School, Hwasun, Korea
}

Future medical technology breakthroughs will build from the incredible progress made in computers, biotechnology, and nanotechnology and from the information learned from the human genome. With such technology and information, computer-aided diagnoses, organ replacement, gene therapy, personalized drugs, and even age reversal will become possible. True 3-dimensional system technology will enable surgeons to envision key clinical features and will help them in planning complex surgery. Surgeons will enter surgical instructions in a virtual space from a remote medical center, order a medical robot to perform the operation, and review the operation in real time on a monitor. Surgeons will be better than artificial intelligence or automated robots when surgeons (or we) love patients and ask questions for a better future. The purpose of this paper is looking at the future medical science and the changes of colorectal surgeons.

Keywords: Medical technology; Artificial intelligence; Mobile device; Telemedicine; Gene therapy; Robot surgery

Medical science is experiencing an exciting evolution, and the ways in which diseases are managed are changing. How we approach these changes creates new opportunities in the fields of surgical diseases, and the conventional roles of surgeons who have treated patients with blood on their gowns will also change. Future medical treatment will mostly be provided by machines and artificial intelligence (AI). Surgeons will enter surgery instructions in a virtual space from a remote medical center, order a medical robot to perform the low anterior resection, and review the surgery in real time on a monitor.

\section{DEVELOPMENT OF MEDICAL SCIENCE}

Just as we no longer ask cardiologists to analyze and interpret electrocardiograms, we will turn to computers like IBM's Watson to analyze medical images and select treatment options for a patient [1]; currently, Watson's diagnostic accuracy is $98 \%$ for

Received: August 30, 2017 - Accepted: October 23, 2017

Correspondence to: Young Jin Kim, M.D.

Department of Surgery, Chonnam National University Hwasun Hospital, Chonnam National University Medical School, 322 Seoyang-ro, Hwasun 58128, Korea

Tel: +82-61-379-7647, Fax: +82-61-379-7661, E-mail: kimyjin@jnu.ac.kr

(C) 2017 The Korean Society of Coloproctology

This is an open-access article distributed under the terms of the Creative Commons Attribution NonCommercial License (http://creativecommons.org/licenses/by-nc/4.0) which permits unrestricted noncommercial use, distribution, and reproduction in any medium, provided the original work is properly cited. colorectal cancer and $100 \%$ for cervix cancer. In addition, the iControl-RP, an automated anesthesia system, has been developed and is about to be commercialized [2]. Because radiology is one of the fastest growing and developing areas of medicine, it might be the specialty in which we can expect to see the biggest developments. In 10 years, AI will create preliminary radiology reports about screenings for everything. In the future, medical holograms will show us lesions right before our eyes [3], and a computer will be able to identify the 12 characteristics of cancer cells so that it will be able to diagnose it more accurately and faster than a pathologist can [4]. One multifunctional machine will be able to detect immediately many medical problems, biomarkers, and symptoms. One quick check-up will tell the physician what percentage of the patient's cells is cancerous or cancer-free [5]. Physicians will be able to use the results from blood tests to detect all types of cancer from a very early stage. By being able to filter tumor cells from blood samples, doctors will be able to diagnose and analyze tumors earlier and without the need for a costly biopsy. Recently, the American Diabetes Association and IBM teamed up for a more personalized therapy for diabetic patients by sharing data on 29 million patients with diabetes and 86 million patients with prediabetes. Another possibility is that a cyber health manager in a computer may reject paying for foods that are bad for diabetic patients when such patients try to buy those foods at a supermarket and pay with a credit card. The future roles of a doctor will be helping patients make better choices and giving them hope while explaining diagnostic results and treatment options, such as sur- 
gery, for which machines will be responsible.

Mobile ultrasound, Google Glass, and other mobile devices have already been adopted in medical fields, and data from those wearable devices will be sent to a medical center where clinical review software will be used for the diagnosis and the treatment of patients [6]. Telemedicine using a health spot center or prehospital care will become more prevalent [7]. Importantly for surgeons, artificial organ development using stem cells and 3-dimensional printing will lead to advances in organ transplantation [8]. The drastically reduced cost of genetic analyses in the future will make the use of those analyses for identifying and correcting genes that are the causes of diseases common place. We will have more and more opportunities for using DNA analyses at the patient's bedside, which should be a must before actually prescribing drugs. I believe that genomics and genetics will be amazing medical tools for preventing and curing diseases, provided that they are used wisely and carefully $[9,10]$. The large amount of available data in the laptop will facilitate the realization of predictive, preventive, personalized, participatory, precise, and persistent (6P) medicine. As a result, the future roles of doctors will be responding to unusual or unexpected accidents, studying new diseases, taking a more humane approach toward patients, dealing with paradigm shifts, controlling computers to prevent errors, updating computers in accordance with human evolution, handling unpredictable and critical situations, and so on.

\section{THE FUTURE OF SURGERY}

Then, what will future surgery look like? If one looks at Google Ngram Viewer, which charts the frequencies of a word used in printed sources for a year, one finds that the frequencies of "laparoscopic surgery" and "robotic surgery" grew dramatically in the 1990s and the 2000s, respectively. Laparoscopic surgery has become more common, and the number of robotic operations is growing in Korea. With known surgical robots, the surgeon is $100 \%$ in control of the robotic system at all times; he or she is able to carry out more precise operations than previously thought possible [11]. A recent animal test conducted using a STAR (smart tissue autonomous robot) showed a comparable or even better result than open, laparoscopic, or robotic surgeries. In the future, surgeons will enter surgery instructions in a virtual space from a remote medical center, order a medical robot to perform the low anterior resection, and review the operation in real time on a monitor [12]. During operations, surgeons will be able to see anatomical structures such as blood vessels and pelvic autonomous nerves without opening the abdomen; therefore, they will able to perform more precise excisions. The malignant cells and tissues will be visible due to fluorescent dye injected before the start of the surgery [13]. With the iKnife (intelligent surgical knife), vaporized smoke is analyzed by using a mass spectrometer to detect the chemicals in the biological sample. This means whether the tissue is malignant or not can be identified in real-time [14]. In my opinion, surgeons have to rethink their work methods for the future and let digital technologies become a bigger part of their professional lives so that they will be able to deliver more precise operations with less harm.

\section{CHANGE OF FUTURE SURGICAL EDUCATION}

Social media have the potential to become huge "mind machines," making it possible to transmit, share, crowdsource (utilize information contributed to a project, usually via the internet and without compensation), and store medical pieces of information either for e-patients or medical professionals, provided that such social platforms are used in a proper way. The education of colorectal surgeons has been changed from the apprentice system to selflearning. The kinds and the methods of operations are multifarious; therefore, surgeons have no time to teach or learn. Smartphone apps, wearable devices, simulation, and telemedicine should be the tools for educating the surgeons of the 21st Century, who will perform an operation by using a virtual reality camera. Everyone will be able to participate in the operation in real time through the medical facility's website and virtual reality and to follow how cancerous tissue is removed from the bowel [15]. The number of Korean doctors per 1,000 population is 2.2 now and less than OECD average. But Korea's growth rate of the number of doctors is $4.17 \%$ yearly and is much higher than the OECD average of $0.82 \%$. Consequently, the number of doctors per 1,000 population will reach the OECD average of 3.3 in 2023 and become higher after then. Technology will replace $80 \%$ of the doctors in the future because machines will be more accurate, objective, and cheaper than a doctor. As fewer surgeons are now needed in the operating room because of laparoscopic surgery and robotic surgery, the era of one surgeon per surgery has begun. Thus, there is no need to educate and produce as many surgeons as in the past.

In conclusion, AI, wearable sensors, virtual reality, medical robots, and gene analyses are completely changing the way patients and doctors think and act about healthcare. The American poet Mary Oliver said, "in this universe we are given 2 gifts: the ability to love and the ability to question." AI can perform many difficult tasks, but lacks the ability to love and the ability to question. The future of surgeons will be brighter when we have love for our patients and ask questions for a better future. Wha-um is a Buddhist term that means decorating the universe with flowers. Wherever we are, if we as surgeons can leave a small mark on this world, just like adding a flower to the universe, we will be successful and our futures will be happier.

\section{CONFLICT OF INTEREST}

No potential conflict of interest relevant to this article was reported. 


\section{REFERENCES}

1. Chen Y, Elenee Argentinis JD, Weber G. IBM Watson: how cognitive computing can be applied to big data challenges in life sciences research. Clin Ther 2016;38:688-701.

2. Nogueira FN, Mendonça T, Rocha P. Positive state observer for the automatic control of the depth of anesthesia-Clinical results. Comput Methods Programs Biomed 2016 Sep 13 [Epub]. https:// doi.org/10.1016/j.cmpb.2016.08.019.

3. Bruckheimer E, Rotschild C, Dagan T, Amir G, Kaufman A, Gelman S, et al. Computer-generated real-time digital holography: first time use in clinical medical imaging. Eur Heart J Cardiovasc Imaging 2016;17:845-9.

4. Ye JJ. Artificial intelligence for pathologists is not near--it is here: description of a prototype that can transform how we practice pathology tomorrow. Arch Pathol Lab Med 2015;139:929-35.

5. Parsons HA, Beaver JA, Park BH. Circulating plasma tumor DNA. Adv Exp Med Biol 2016;882:259-76.

6. Sahyouni R, Moshtaghi O, Tran DK, Kaloostian S, Rajaii R, Bustillo D, et al. Assessment of Google Glass as an adjunct in neurological surgery. Surg Neurol Int 2017;8:68.

7. Kelton DK, Szulewski A, Howes D. Real-time video telemedicine applications in the emergency department: a scoping review of literature. CJEM 2017 Aug 22:1-9 [Epub]. https://doi.org/10.1017/ cem.2017.382.

8. Kang K, Kim Y, Lee SB, Kim JS, Park S, Kim WD, et al. Three-di- mensional bio-printing of hepatic structures with direct-converted hepatocyte-like cells. Tissue Eng Part A 2017 Jul 20 [Epub]. https://doi.org/10.1089/ten.TEA.2017.0161.

9. Pasternak AL, Ward KM, Luzum JA, Ellingrod VL, Hertz DL. Germline genetic variants with implications for disease risk and therapeutic outcomes. Physiol Genomics 2017;49:567-81.

10. O’Donnell PH, Ratain MJ. Germline pharmacogenomics in oncology: decoding the patient for targeting therapy. Mol Oncol 2012;6: 251-9.

11. Park S, Kim NK. The role of robotic surgery for rectal cancer: overcoming technical challenges in laparoscopic surgery by advanced techniques. J Korean Med Sci 2015;30:837-46.

12. Avgousti S, Christoforou EG, Panayides AS, Voskarides S, Novales C, Nouaille L, et al. Medical telerobotic systems: current status and future trends. Biomed Eng Online 2016;15:96.

13. Kim J, Do EJ, Moinova H, Bae SM, Kang JY, Hong SM, et al. Molecular imaging of colorectal tumors by targeting colon cancer secreted protein-2 (CCSP-2). Neoplasia 2017;19:805-16.

14. St John ER, Balog J, McKenzie JS, Rossi M, Covington A, Muirhead L, et al. Rapid evaporative ionisation mass spectrometry of electrosurgical vapours for the identification of breast pathology: towards an intelligent knife for breast cancer surgery. Breast Cancer Res 2017;19:59.

15. Nagendran M, Gurusamy KS, Aggarwal R, Loizidou M, Davidson BR. Virtual reality training for surgical trainees in laparoscopic surgery. Cochrane Database Syst Rev 2013;(8):CD006575. 